\title{
correspondence
}

\section{Palaeoanthropology: more than the sum of its parts}

SiR,--I regret that my colleagues were so disturbed by the (perhaps) alarmist title of my article "Is British physical anthropology dying?" (19 January, page 196). I certainly did not intend to under-value their contributions to physical anthropology in its widest sense, but rather to draw attention to the need for institutional resources to be directed to teaching and research in palaeoanthropology. In view of the misunderstanding which my article evoked, I will repeat my propositions in a somewhat different form:

- Palaeoanthropology is today a very different science from the study of fossil man as it was taught 30 years ago. It is now far more than the anatomical study and analysis of fossils and has become a holistic science of early man.

- For this reason it should find its home in anthropology departments where palaeoanthropologists can rub shoulders with archaeologists and social anthropologists, as well as all other kinds of physical anthropologists. I believe that palaeoanthropology is now a central part of the science of man and the most fundamental of the anthropological sciences: the present can only be understood as a product of the past. It requires far greater representation in our curricula.

The situation described at University College seems to me almost idealexcept in one respect: that as a result of "historical circumstances"

palaeoanthropology is taught by two "temporary lecturers" (who both happen to be US citizens). This exemplifies perfectly the point $I$ was trying to make: we desperately need further institutional support for

palaeoanthropology in this country.

Very valuable research is being carried out in both museums and anatomy departments-research appropriate to these establishments and essential to the progress of

palaeoanthropology. But I believe that today palaeoanthropology is more than taxonomy, more than anatomy, and it is more than human biology. It is a rapidly developing and increasingly popular discipline. It is the framework for the study of mankind, as it traces the history of human anatomy,

behaviour, society, technology and ecology-all part of the complex system of human evolution. Yours faithfully B. G. Campbell

Hunstanton, Norfolk, UK

\section{Les écologistes and the French elections}

SIR,-We were surprised by the article 'Ecologists lose in French elections'
(30 March, page 393). The author is free to give his own interpretation about the ecological results during the elections, but, in a scientific magazine, he must be careful about fact.

- There has never been an ecological group called 'les Verts' (the Greens). It is the popular name in France for all ecologists.

-The ecologists never obtained $5 \%$ of the votes during the municipal elections last year, but a little more than $1 ;$ on a national level, because they did not have many candidates.

-This year, they doubled the score with $2.2 \%$ of the votes.

- Brice Lalonde never called to vote on the second turn for the left-wing opposition.

What is true is that, each ecological candidate won on average $5 \%$ of the votes in his area. There were about 200 ecology candidates in 500 electoral areas. This was less than during the municipal elections.

\section{Yours faithfully,}

JEAN-J ACQUES PORCHEZ

Les Amis de la Terre de Paris, France

\section{Saccharin - the risks and benefits}

SIR,-We were interested in Dr Cohen's comments ( 9 February, page 492). Cohen quotes our paper (Lancet 17 September, 1978, page 578) as providing data on the risk of bladder cancer if the United States population were to ingest one diet soft drink each day throughout their lives. We question his conclusion that this would induce an extra 1,200 bladder cancers per year, primarily because we doubt whether the data available on the carcinogenicity of artificial sweeteners is in an appropriate form to perform risk-benefit analyses, as too many extrapolations are required.

An example of an analysis which might be performed which is at least as defensible as that of Dr Cohen is given in the table. We have assumed: that the risk for males who consumed artificial sweeteners in tablet or drop form in our study can be extrapolated to the consumption of diet soft drinks; that individuals commence consuming the equivalent of one tablet of saccharin a day from the age of 16 and continue this throughout their lifetime; that there is a twenty year latent period for the effect; and that there is a linear dose-response relationship permitting extrapolation of our data to younger and to older ages.

Applying the rates of bladder cancer for all races and centres in males from the US Third National Cancer Survey and the calculated risk ratios to the population of males in the United States from the 1970 census (third column of the table) we derive an expectation for a total of 67,309 cases with saccharin to 19,626 without. As the rates we use are mean annual incidence rates, the excess cases in males from consumption of saccharin could be 47,000 a year. Thus, any comparison with obesity must be regarded in a different light even if one is prepared to concede the debatable point that diet soft drinks are valuable as a means of combating obesity.

In addition, however, the population is not exposed to artificial sweeteners only through consumption of diet soft drinks. As a result of the publicity that followed our results, we learnt that the food industry was planning the introduction of a new generation of prepared foods for which the sweetening agent was to be saccharin rather than sucrose. The reason for the preference was not a desire to reduce the risks of obesity to the population, but rather that sucrose is more expensive and therefore the potential economic gain would be greater if artificial sweeteners were used. Our concern therefore, even though we do not claim that our results are definitive (Lancet, 10 December, 1977 , page 1221 ) is over the unwitting exposure of large populations to a potentially hazardous substance. The banning of saccharin as a food additive is, therefore, an appropriate course of action.

$$
\text { Yours faithfully, }
$$

A. B. Miller Geoffrey R. Howe

National Cancer Institute of Canada.

Toronto

Incidence of Bladder Cancer and Effect of Regular Consumption of Saccharin (equivalent to one tablet a day from the age of 15)

\begin{tabular}{ccccccc}
\hline $\begin{array}{c}\text { Age } \\
\text { group }\end{array}$ & $\begin{array}{c}\text { Rate per } \\
\mathbf{1 0 0 , 0 0 0}\end{array}$ & $\begin{array}{c}\text { Population } \\
\text { (US males) }\end{array}$ & $\begin{array}{c}\text { Number of } \\
\text { cases }\end{array}$ & $\begin{array}{c}\text { Cumulative } \\
\text { saccharin } \\
\text { consumption }\end{array}$ & $\begin{array}{c}\text { Risk } \\
\text { ratio }\end{array}$ & $\begin{array}{c}\text { Number of } \\
\text { cases (with } \\
\text { saccharin) }\end{array}$ \\
$\mathbf{3 5 - 3 9}$ & 3.0 & $5,412,423$ & 162 & 8,218 & 1.5 & 243 \\
$40-44$ & 6.8 & $5,818,813$ & 396 & 10,044 & 1.8 & 713 \\
$45-49$ & 13.4 & $5,851,334$ & 784 & 11,871 & 2.1 & 1,646 \\
$50-54$ & 23.1 & $5,347,916$ & 1,235 & 13,697 & 2.4 & 2,964 \\
$55-59$ & 39.0 & $4,765,821$ & 1,859 & 15,524 & 2.8 & 5,205 \\
$60-64$ & 65.9 & $4,026,972$ & 2,654 & 17,350 & 3.1 & 8,227 \\
$65-69$ & 106.5 & $3,122,084$ & 3,325 & 19,177 & 3.4 & 11,305 \\
$70-74$ & 145.2 & $2,315,000$ & 3,361 & 21,003 & 3.7 & 12,436 \\
$75+$ & 196.4 & $2,978,624$ & 5,850 & 23,741 & 4.2 & 24,570 \\
Total & - & - & $\underline{19,626}$ & - & - & 67,309 \\
\hline
\end{tabular}

